\title{
DO TRABALHO COM GÊNEROS DE TEXTO/DISCURSO NO ENSINO DE LIINGUA MATERNA: UM PERCURSO DE CONTINUIDADES, MUDANÇAS E POSSIBILIDADES
}

\author{
FROM WORKING WITH TEXT/DISCOURSE GENRES IN PORTUGUESE \\ LANGUAGE TEACHING: A JOURNEY OF CONTINUITIES, CHANGES AND \\ POSSIBILITIES
}

\author{
Ana Maria de Mattos Guimarães \\ Universidade do Vale do Rio dos Sinos, São Leopoldo, Rio Grande do Sul, Brasil \\ anamguima2012@gmail.com \\ Anderson Carnin \\ Universidade do Vale do Rio dos Sinos, São Leopoldo, Rio Grande do Sul, Brasil \\ anderson.carnin@gmail.com
}

\begin{abstract}
Resum0: Este artigo tem como objetivo apresentar uma reflexão crítica acerca de nosso percurso como professores e formadores de professores de língua materna em relação ao trabalho com gêneros de texto/discurso em contexto escolar, mais especificamente, no ensino de língua portuguesa. Trata-se, pois, de uma (meta)análise sobre os desafios vivenciados no trabalho com gêneros de texto/discurso no percurso entre a formação (acadêmica) e a prática (de sala de aula). A reflexão sobre esse percurso tem como objetivo principal fazer um balanço sobre os esforços de pesquisa que vimos construindo nesse âmbito nos últimos 20 anos, os desafios enfrentados quando se faz pesquisa na interação com contextos escolares de ensino e de aprendizagem de língua materna, os fundamentos teórico-metodológicos por nós mobilizados para essa ação e, partir desse movimento, refletir sobre os desafios e perspectivas que hoje se desdobram como possibilidades de futuro.

Palavras-chave: Gêneros de Texto/Discurso; Formação de Professores; Ensino de Língua Portuguesa
\end{abstract}

Abstract: This article aims to present a critical reflection about our journey as teachers and trainers of Portuguese language teachers in relation to working with text/discourse genres in the school context, more specifically, in the teaching of Portuguese. It is, therefore, a (meta) analysis about the challenges experienced in working with genres of text/discourse in the journey between training (academic) and practice (in the classroom). The reflection on this journey has as main objective to make an assessment about the research efforts that we have been building in this scope, in the last 20 years, the challenges faced when doing research in the interaction with school contexts of teaching and learning of Portuguese language, the theoretical-methodological foundations mobilized by us for this action and, based on this movement, reflect on the challenges and perspectives that today unfold as possibilities for the future.

Keywords: Text/Discourse Genres; Teacher training; Portuguese Language Teaching

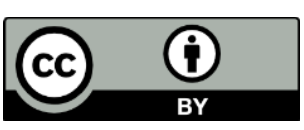




\title{
1 SITUANDO A REFLEXÃO
}

\author{
Mera mudança não é crescimento. Crescimento é \\ a síntese de mudança e continuidade, e onde não \\ há continuidade não há crescimento. \\ C. S. Lewis.
}

Este texto é destinado à reflexão crítica acerca de nosso ${ }^{1}$ percurso como professores de língua materna (e formadores de professores) em relação ao trabalho com gêneros de texto/discurso em contexto escolar, mais especificamente, no ensino de língua portuguesa. Essa não é, no entanto, apenas uma mirada sobre o que já vivenciamos nesse campo, uma forma de - apesar de muito importante - historicizar o percurso de nosso grupo de pesquisa, uma "visada saudosista" sobre o que já foi experienciado no contexto de atuação profissional em que nos inserimos. A reflexão sobre esse percurso, compartilhado com muitos colegas (especialmente aqueles que também fazem/fizeram parte do GT Gêneros de Texto/Discurso da ANPOLL) tem como objetivo principal fazer um balanço sobre os esforços de pesquisa que vimos construindo nesse âmbito, os desafios enfrentados quando se faz pesquisa na interação com contextos escolares de ensino e de aprendizagem de língua materna, os fundamentos teóricometodológicos por nós mobilizados para essa ação e, a partir desse movimento, refletir sobre os desafios e perspectivas que hoje se desdobram como possibilidades de futuro. Nesse sentido, a reflexão aqui empreendida busca contribuir para o diálogo acerca do trabalho com gêneros de texto/discurso e práticas de linguagem considerando nossa experiência de pesquisa e formação sobre esse tema.

Antes de mais nada, cumpre ressaltar que nosso interesse pela temática do trabalho com gêneros de texto/discurso remonta ao início dos anos 2000, época em que constituímos grupo de pesquisa preocupado com a formação de professores que incorporassem em suas práticas de ensino de língua materna as possibilidades de didatização de gêneros. Essa era uma questão ainda bastante nova no contexto escolar brasileiro, dada a (então) recente homologação dos Parâmetros Curriculares Nacionais: Língua Portuguesa para o Ensino Fundamental, no ano de 1998, e o efeito que a publicação desse documento oficial teve sobre as práticas de ensino de língua materna - e mesmo sobre os currículos escolares, sobre os cursos de licenciatura, na produção de materiais didáticos, entre outros. A institucionalização/oficialização do trabalho com gêneros de texto/discurso como objetos de ensino (BRASIL, 1998) fomentou o desenvolvimento de diversas pesquisas e publicações sobre esse tema (p. ex., ROJO, 2000; BARBOSA, 2001; DIONISIO; MACHADO; BEZERRA, 2002; MACHADO, 2004; GUIMARÃES; CAMPANI-CASTILHOS; DREY, 2008). Foi, à semelhança de muitas dessas pesquisas, que, a partir da visão teórica do Interacionismo Sociodiscursivo (BRONCKART, 1999; DOLZ; SCHNEUWLY, 1999), procuramos, naquele momento, adentrar na questão da didatização de gêneros e sua relação com o desenvolvimento do processo de construção social da escrita (GUIMARÃES, 2003). Em linhas de continuidade, nossas pesquisas seguiram investigando a questão da escrita e seu desenvolvimento, avançando na direção do(s) impacto(s) do trabalho com sequências didáticas (DOLZ; NOVERRAZ; SCHNEUWLY, 2004) no ensino de língua materna, cotejando a experiência com esse dispositivo didático em dois ambientes sociais diversos. $\mathrm{O}$ foco, nesses dois primeiros

\footnotetext{
${ }^{1}$ Certamente, esse percurso foi/é construído na interação diária com os/as demais membros/as de nosso grupo de pesquisa, com alunos/as e orientandos/as, além, é claro, de nossos pares, especialmente nos produtivos encontros por ocasião do SIGET - Simpósio Internacional de Estudos de Gêneros Textuais e das reuniões do GT Gêneros Textuais/Discursivos da ANPOLL, a quem somos muito gratos.
} 
momentos, recaiu sobre o aluno, sua aprendizagem e o desenvolvimento de suas capacidades de linguagem. Num segundo momento, a partir dessa experiência, o trabalho com professores de língua portuguesa ganhou corpo em nossos esforços de pesquisa, uma vez que resultados de pesquisa nos mostravam uma tendência à ruptura: o professor, quando sozinho em sua prática, não se sentia seguro o suficiente para desenvolver autonomamente um projeto de ensino/sequência didática baseado/a no trabalho com gêneros de texto/discurso. Desse segundo momento é que derivou nosso primeiro movimento de mudança (no foco analítico) e de continuidade (no esforço de aproximar o trabalho com gêneros de texto/discurso do fazer cotidiano de sala de aula). Em meados de 2009, iniciamos novo projeto de pesquisa, focado em compreender como se desenvolve a profissionalidade de futuros professores de língua portuguesa, analisando mais detidamente a questão de seu trabalho real (BRONCKART, 2009) com gêneros de texto/discurso em sala de aula.

Como trabalhamos com alunos de graduação em fase de estágio de docência, esse segundo momento também nos permitiu uma maior aproximação com os professores que, já formados, atuavam em sala de aula e cujos modos de fazer, não raramente, conflitavam com as orientações oficiais vigentes ou mesmo com as práticas que os futuros professores procuravam construir em suas salas de aula. Na esteira dessa questão, as linhas de continuidade que fomos construindo levaram-nos à questão da formação continuada de professores, buscando ressignificar a relação de professores em atuação tanto com a universidade quanto com o trabalho assentado na didatização de gêneros de texto/discurso. Desse trabalho com formação continuada decorre também nosso esforço mais recente de pesquisa, que procura articular a questão do trabalho com gêneros de texto/discurso à problemática do desenvolvimento profissional docente.

Como se vê, a didatização de gêneros foi (e segue sendo) nosso primeiro ângulo de entrada no trabalho de pesquisa e de intervenção, questão que será explorada na primeira seção deste texto, quando nos debruça(re)mos sobre nossa perspectiva acerca dos Gêneros e ensino de língua materna, evidenciando tanto nossos principais fundamentos teóricos, quanto resgatando alguns de nossos primeiros resultados de pesquisa acerca desse tema. No segundo momento exploramos a questão do trabalho com Gêneros e a formação inicial de professores de língua materna, procurando evidenciar os diálogos que vimos construindo, nesses quase 20 anos de investigação, entre a pesquisa aplicada e a formação de novos professores de língua materna orientados pelas evidências que o trabalho de campo têm nos permitido apreender, sistematizar e ressignificar quando se pensa sobre os modos de construir novas formas de atuação no trabalho docente, especialmente no contexto da formação inicial universitária. $\mathrm{O}$ terceiro movimento deste texto dedica-se ao nosso trabalho mais recente: Gêneros $e$ desenvolvimento profissional docente. A partir de projetos de pesquisa dedicados à questão da formação continuada de professores, debruçamo-nos tanto a investigar os modos de apropriação por si e para si de professores em atuação na rede pública de ensino do trabalho com gêneros de texto quanto a analisar os efeitos desenvolvimentais dessa apropriação (MACHADO; LOUSADA, 2010) no que diz respeito à proposição de (novas) formas de atuação pedagógica e ao seu desenvolvimento profissional.

É na esteira desses três grandes movimentos que buscamos pôr em diálogo as vozes que sustenta(ra)m nossos esforços de pesquisa sobre/a partir da didatização de gêneros textuais/discursivos e propomos uma análise crítica de nosso percurso de investigação. É na reflexão crítica sobre a experiência de trabalho e de pesquisa que também buscamos, ao final, fomentar o diálogo com outras vozes, outros contextos e outros pesquisadores, na expectativa de que, juntos, novas linhas de mudança elou de continuidade possam ser (co)construídas e quiçá permitam o crescimento das pesquisas nessa área nos próximos anos. 


\section{GÊNEROS E ENSINO DE LÍNGUA MATERNA}

Nossa relação com a sala de aula de língua materna como lócus de ensino e de pesquisa tem longa trajetória. Contudo, neste texto, vamos focalizar a entrada nesse espaço à luz da noção de gênero de texto/discurso e da assunção dos gêneros como objetos de ensino nas aulas de língua portuguesa. Foi um projeto cujo objetivo era reconhecer práticas de ensino/entender suas formas de organização didática/formar professores que estivessem preocupados em centrar suas aulas na produção escrita, especialmente no trabalho com o desenvolvimento da narrativa e o processo de construção social da escrita em contexto escolar (GUIMARÃES, 2003) que nos levou ao trabalho sistemático com gêneros de texto ${ }^{2}$ proposto pela Escola de Genebra (BRONCKART, 1999; DOLZ; SCHNEUWLY, 1999). Nesse projeto, que partiu da observação da realidade de duas escolas situadas em realidades sociais diversas de letramento, nossa primeira constatação foi que em ambas a aula de língua portuguesa não se organizava em torno do trabalho com gêneros de texto como objeto de ensino, e propusemos algumas formas de mitigar essa questão (GUIMARÃES, 2004; GUIMARÃES; CORDEIRO; AZEVEDO, 2006).

Em nosso trabalho de pesquisa, partimos da abordagem interacionista sociodiscursiva (ISD) (BRONCKART, 1999; 2006; 2008), que toma a linguagem como central para a análise das condutas humanas e compreende que estas constituem redes de atividades desenvolvidas num quadro de interações diversas, materializadas através de ações de linguagem, as quais se concretizam discursivamente dentro de um determinado gênero. Essa asserção pode aqui ser desdobrada em três partes, igualmente importantes para nossa discussão acerca da noção de gênero que assumimos e sua relação com o ensino de língua materna: $(i)$ toda e qualquer ação de linguagem - ou seja, tudo aquilo que produzimos quando interagimos verbalmente - só é possível por meio de um gênero de texto, evidenciando a dimensão praxiológica que esse conceito assume no quadro interacionista sociodiscursivo; (ii) embora do ponto de vista teórico essa seja uma relação bastante evidente, cumpre reforçar que o foco da abordagem interacionista sociodiscursiva recai sobre as ações verbais e não-verbais das pessoas quando em interação, e que a noção de gênero, apesar de central para o quadro teórico, não foi pensada como unidade privilegiada de análise deste e; (iii) a extensão dessa noção (de gênero de texto) ao espaço escolar deriva da relação dialética que os principais autores da teoria têm com a Didática de Línguas na Universidade de Genebra e que, aos poucos, foi sendo traduzida para o contexto brasileiro a partir de relações de pesquisa estabelecida por pesquisadores do campo da Linguística Aplicada (p. ex., ROJO, 2000; MACHADO, 2004, entre outros).

Acerca da dimensão praxiológica que a noção de gênero de texto por nós assumida engendra, lembramos da ponderação de Machado (2005, p. 241) que, ao discutir como o quadro do ISD foi definindo paulatinamente essa noção, lembra-nos de que "gênero de texto não se define: é o que existe". É importante entendermos que, no quadro do ISD, quando se fala em texto, remete-se à compreensão de que "toda a unidade de produção de linguagem situada, acabada e autossuficiente (do ponto de vista da ação ou da comunicação). Na medida em que todo texto se inscreve, necessariamente, em um conjunto de textos ou em um gênero, adotamos a expressão gênero de texto em vez de gênero de discurso" (BRONCKART, 1999, p. 75, grifo do autor). Outra questão importante sobre isso, discutida mais recentemente, é que, para

\footnotetext{
${ }^{2}$ A partir deste momento, como assumimos nossa base teórica, passaremos a utilizar a expressão "gêneros de texto" por uma questão de coerência à nossa afiliação ao quadro do ISD. Quando nos dirigirmos ao conceito, mais amplamente, sem recorrer a uma determinada afiliação teórica, seguiremos usando a expressão "gêneros de texto/discurso", já que é ela que nomeia o grupo de trabalho (GT) da ANPOLL do qual fazemos parte e tende a abranger mais amplamente distintas afiliações teóricas que se reconhecem na noção de gênero. Uma discussão mais adensada sobre o que caracteriza cada uma dessas variações conceituais/afiliações teóricas pode ser encontrada, por ex., em Bawarshi e Reiff (2013) ou, especialmente para o contexto brasileiro, em Bezerra (2017).
} 
Bronckart (2017, p. 48), a genericidade somente é atestada pelos textos, um dos motivos que o leva a reiterar a escolha por empregar o termo gêneros de texto no âmbito do ISD. A noção de gênero de texto assumida pelo ISD tem como ponto de partida a definição apresentada por Volochinov, ainda em 1930, de que

[...] o enunciado, considerado como uma unidade de comunicação e totalmente semântico, se constitui e se torna realidade precisamente em uma interação verbal determinada e produzida em uma certa relação de comunicação social. Dessa forma, cada um dos tipos de comunicação social [...] organiza, constrói e finaliza, de modo específico, a forma gramatical e estilística do enunciado assim como a estrutura do tipo do qual depende, nós a designaremos de agora em diante com o termo gênero (VOLOCHINOV, 1981 [1930], p. 289-290).

Reiteramos, então, que é incontornável para o ISD a dimensão praxiológica que a noção de gênero de texto comporta e que, a partir disso, construiu-se "uma abordagem descendente dos fatos linguageiros, que coloca em primeiro plano a práxis, isto é, a dimensão ativa, prática, das condutas humanas em geral e das condutas verbais em particular" (BRONCKART, 2007, p. 21). É a partir dessa abordagem descendente, que vai do social ao linguístico, que se delimita a unidade de análise principal do ISD: os textos. Isso, contudo, não significa limitar a abordagem teórica a esse exercício analítico-descritivo da produção verbal. Ao assumir a noção de gênero de texto como um pré-construto social necessário ao agir linguageiro, como um conjunto de "modelos de referência" para a interação verbal (BRONCKART, 1999), o ISD compreende que todo gênero de texto pode ser considerado como mais ou menos pertinente para uma determinada situação/ação de linguagem. Essa pertinência pode ser analisada, dentre outros caminhos, por meio dos textos que materializam a noção de gênero de texto e que são construídos em situação de interação social.

A distinção dos elementos que podem ser analisados quando se toma o texto como unidade principal de análise permite também compreender a ênfase que a proposta das sequências didáticas (DOLZ; NOVERRAZ; SCHNEUWLY, 2004) dá ao texto quando se trabalha com gêneros em ambiente escolar. Segundo Schneuwly e Dolz (2004, p. 74), "é através dos gêneros que as práticas de linguagem materializam-se nas atividades dos aprendizes". Dessa hipótese aventada pelos autores é que se origina a compreensão de que o ensino de língua(gem) na escola deve considerar o gênero como ponto de partida para um ensino não fragmentário das práticas de linguagem. Ainda, segundo os autores, o gênero "pode ser considerado como um megainstrumento que fornece um suporte para a atividade nas situações de comunicação, e uma referência para os aprendizes" (SCHNEUWLY; DOLZ, 2004, p. 75). Do mesmo modo, é assumido pelos autores que o trabalho com gêneros na escola requer um desdobramento destes: todo e qualquer gênero, ao adentrar no espaço escolar como objeto de ensino, deixa de ser apenas um instrumento de comunicação, pois passa a ser também um objeto de ensino e de aprendizagem. Em nosso entendimento, transformar o gênero em objeto de ensino e de aprendizagem na perspectiva dos autores não prescinde da necessidade de considerar elementos ligados à gênese do conceito no âmbito do ISD, ou seja, à sua dimensão praxiológica. $\mathrm{O}$ foco dos autores do procedimento no desenvolvimento das capacidades de linguagem (SCHNEUWLY; DOLZ, 2004) dos aprendizes por meio do trabalho com sequências didáticas não invalida, grosso modo, as contribuições que o procedimento também pode oferecer ao desenvolvimento dos letramentos dos alunos, especialmente os letramentos escolares. Ainda que reconheçamos a pertinência das críticas ao demasiado foco das sequências didáticas às questões linguístico-textuais do trabalho com gêneros, é inegável que tal procedimento didático foi a porta de entrada primeira do trabalho com gêneros na escola brasileira, especialmente a partir da publicação dos Parâmetros Curriculares Nacionais: 
Língua Portuguesa (BRASIL, 1998), e tem contribuído até hoje para que avancemos continuamente na direção de consolidar o trabalho com gêneros em nosso cenário educacional. Considerando isso, voltemos, então à nossa experiência com gêneros e ensino de língua materna, especialmente a partir de projetos de pesquisa que desenvolvemos entre 2003 e 2006 (respectivamente, "Desenvolvimento da narrativa e o processo de construção social da escrita" e "A construção da escrita em ambientes sociais diversos: o Interacionismo Sociodiscursivo em questão"). Assim como muitos pesquisadores envolvidos com o campo do ensino e da aprendizagem de língua materna em contexto escolar, à época, nossa experiência inicial com sequências didáticas foi realizada através de um trabalho longitudinal com alunos de Ensino Fundamental, mais bem relatada em Guimarães (2006). Os resultados da análise das produções dos alunos, ao longo do acompanhamento da $3 .^{\mathrm{a}}$ até a $5 .^{\mathrm{a}}$ série (atualmente, $2 .^{\circ}$ a $4 .^{\circ}$ ano do Ensino Fundamental), após a aplicação de sequências didáticas, apontaram transformações em suas capacidades de linguagem, sobretudo no que diz respeito às dificuldades relativas à organização de sequências narrativas e ao domínio do conteúdo temático próprio dos gêneros trabalhados (no caso, nas três séries, o foco foi no domínio da narração a partir de gêneros como conto de fada, peça de teatro infantil e narrativa de detetive). Essa primeira experiência nos permitiu reforçar a certeza de que o trabalho com gêneros é realmente muito produtivo para o ensino de língua materna em uma perspectiva que assume uma concepção de linguagem como interação (GERALDI, 1984; MATÊNCIO, 1994; entre outros) e reforça o papel da escola (em geral) e das aulas de língua portuguesa (em específico) em dar acesso aos alunos à cultura da escrita e a tudo o que isso implica, especialmente em um país como o Brasil.

Essa primeira incursão de pesquisa no trabalho com gêneros em sala de aula de língua portuguesa, contudo, nunca foi apenas um caminho de flores. Há pedras no caminho, e ao pesquisador, especialmente, cabe o papel de encontrar o caminho do meio: não se fixar apenas nas pedras, tampouco apenas no caminho (GUIMARÃES, 2010). Em nossas reflexões ao final daquele primeiro projeto de aproximação entre o trabalho com gêneros e o ensino de língua materna, já compreendíamos que:

[...] é preciso considerar que na elaboração de sequências didáticas, o papel do professor é fundamental. Essa foi justamente a maior dificuldade encontrada na experiência relatada. Os resultados animaram os três docentes que participaram dessa caminhada, mas não garantiram sua adesão como proponentes de novas sequências didáticas. Encontra-se, nessa questão, o obstáculo mais sério à didatização de gêneros, tal como vista pelo Interacionismo Sociodiscursivo. Há um suporte teórico muito forte que deve respaldar a ação didática, mas que pode permanecer distante do professor de ensino fundamental se este não receber apoio específico com esse fim. Ao mesmo tempo, é preciso estar alerta para o que os professores dizem ser trabalhar com gênero (GUIMARÃES, 2005), pois deve estar presente a diferença entre trabalho sobre um gênero, enquanto unidade comunicativa adaptada a uma dada situação, e trabalho sobre as sequências que estão presentes neste mesmo gênero de texto. (GUIMARÃES, 2006, p. 370).

Esse trabalho inicial de pesquisa, aproximando o trabalho com gêneros de texto, à luz do ISD e do trabalho com sequências didáticas, permitiu que observássemos também a importância de o trabalho com professores partir de concepções fundantes, uma das quais, sem dúvida alguma, é a de gênero de texto/discurso. Essa convicção e a nossa contínua busca pela melhoria das práticas de ensino de língua materna em sala de aula é que nos levaram a um segundo movimento de pesquisa, em que focalizamos o trabalho com gêneros já na formação inicial de professores. Nossa próxima seção dedica-se a situar as linhas de continuidade de nossas pesquisas acerca desse tema. 


\section{GÊNEROS E FORMAÇÃO INICIAL DE PROFESSORES DE LÍNGUA MATERNA}

A insegurança em desenvolver projetos de ensino baseados na noção de gênero de texto revelada pelas professoras com que trabalhamos entre 2003 e 2006 era também uma questão para futuros professores. Como a licenciatura em Letras prepara alunos para assumirem o papel de professores? É a constituição inicial de sua profissionalidade objeto de reflexão à luz dos estudos sobre o trabalho docente? Questões como essas nos levaram a conduzir um projeto de pesquisa intitulado "Constituição da Profissionalidade do Professor de Língua Portuguesa: a formação de futuros docentes em foco" (2009-2012), em que, a partir do acompanhamento de alunas-professoras de uma universidade confessional da região sul do Brasil, em dois momentos de estágio, em dois semestres diferentes, procuramos fazer avançar a compreensão analítica sobre como o trabalho do professor em formação inicial com gêneros de texto impacta na constituição da profissionalidade docente. Nesse sentido, o foco analítico nesse momento de nossas pesquisas recaiu sobre atividades de linguagem que se concretizam em textos no contexto de situações do agir docente no cenário de sala de aula. À luz das discussões sobre o trabalho do professor que pesquisadores ligados aos ISD passaram também a realizar, o projeto levou em consideração a relação entre o trabalho prescrito, o real e o representado pelos próprios participantes da pesquisa. Se outros pesquisadores ligados ao quadro teórico interacionista sociodiscursivo também exploravam esse vértice de pesquisa, especialmente na inter-relação do ISD com o quadro das Ciências do Trabalho (Ergonomia da Atividade, Clínica da Atividade, Psicologia do Trabalho, entre outras), nossa opção, naquele momento, foi instaurar um diálogo entre nossa base teórica principal com propostas teórico-analíticas advindas da Sociolinguística Interacional e da Análise da Conversa de base Etnometodológica (GUIMARÃES, 2009; GUIMARÃES; DREY; CARNIN, 2012; DREY; GUIMARÃES, 2012; 2016).

Neste artigo, no entanto, vamos nos deter em um movimento específico de pesquisa que focalizou o trabalho com produção de texto, ou melhor, a (co)construção da escrita como objeto de ensino, em sala de aula, à luz da noção de gênero de texto, por duas alunas-professoras que colaboraram com uma de nossas pesquisas (CARNIN, 2011). Desenvolveu-se, nessa investigação, uma análise linguística das interações de sala de aula a partir de pressupostos teórico-analíticos advindos do quadro do ISD. A análise qualitativa dos dados enfocou dois níveis da textualidade (MACHADO; BRONCKART, 2009), o organizacional e o enunciativo, amparando-se na identificação e análise de elementos linguísticos presentes na verbalização das alunas-professoras para desvelar as relações entre as escolhas linguísticas/textuais realizadas e a emergência do trabalho real e da profissionalidade docente em contexto de formação inicial de professores. Do ponto de vista didático (DOLZ, 2009; DOLZ; GAGNON; DECÂNDIO, 2010), a análise então empreendida considerou a presença de gestos didáticos (AEBY DAGHÉ; DOLZ, 2007; GOMES-SANTOS, 2010) e sua relação com o desenvolvimento da profissionalidade das alunas-professoras em formação inicial e que colaboraram com nossa pesquisa. Apenas a título de exemplificação, apresentamos a seguir dois pequenos excertos do conjunto de dados ${ }^{3}$ explorados na pesquisa de 2011, com vistas a auxiliar na compreensão dos resultados que apresentamos na sequência e na discussão que estamos fazendo sobre o trabalho com gêneros de texto no ensino de língua materna. Trata-se de uma aula de produção textual destinada ao trabalho com o gênero artigo de opinião, em uma turma de $8 .^{\circ}$ ano do Ensino Fundamental, durante o estágio de Liana (nome fictício).

\footnotetext{
${ }^{3}$ Foram empregadas, nos excertos apresentados neste texto, as convenções de transcrição propostas por Schnack, Pisoni e Ostermann (2005).
} 
Excerto 1 - a introdução da proposta de produção textual

795 LIANA: 796 ALUNA1: 797 ALUNA2: 798 LIANA: do autor. o quê que vocês vão fazer (.) depois do intervalo?

dá a opinião nossa

UM TEXTO COM A NOSSA opinião sobre [a mentira]

((alunos voltam a conversar)) [um pequeno] artiguinho de opinião.

Excerto 2 - a explicação acerca do gênero solicitado na proposta de produção textual

888 LIANA:

889

890

891

892

893

894

como é que vocês vão <fazer> esse artigo de opinião?
((nesse momento, enquanto fala vai escrevendo alguns tópicos no quadro))
ele tem que ter (.) uma introdução ((vai escrevendo introdução no quadro $))(1 \mathrm{seg}$.
do assunto (.) que vocês vão dizer $(2$ seg.)
ele tem que ter os argumentos ((vai escrevendo argumentos) $(5 \mathrm{seg}$.
e depois ((vai escrevendo conclusão)) ele vai ter que ter uma conclusão $(2 \mathrm{seg}$.
depois do que vocês apresentaram a que conclusão vocês
chegam à conclusão >a mentira< é certa ( 1 seg.) ou ela é errada?
((ela se vira em direção aos alunos e, enquanto fala, aponta para os escritos no quadro)).

No desenvolvimento do projeto em discussão, interessávamo-nos pela descrição do trabalho real, articulando análise linguística e didática do fenômeno interacional de sala de aula, procurando descrever e analisar o(s) modo(s) de construção do objeto de ensino produção textual em sala de aula. No contexto deste artigo, gostaríamos de realçar um outro aspecto que os dados acima nos permitem ilustrar, considerando o avanço de nossas reflexões.

Liana, em seu projeto de ensino, construiu sua proposta de trabalho à luz daquilo que poderíamos chamar de uma adaptação da proposta de didatização de gêneros de Dolz, Noverraz e Schneuwly (2004): a sequência didática. Ainda que os dois excertos acima mostrem apenas fragmentos da aula destinada à produção inicial do gênero artigo de opinião, compete ressaltar que a aluna-professora seguiu, nas aulas seguintes, a proposta modular de trabalho com o gênero a partir da identificação na produção inicial dos alunos de quais elementos do gênero escolhido poderiam ser ensinados em seu trabalho docente para desenvolver as capacidades de linguagem dos alunos e permitir que ao final de seu projeto eles se tornassem produtores mais competentes do gênero por ela selecionado. Na análise mais fina das interações de sala de aula, pudemos descrever mais detidamente as escolhas realizadas por alunas-professoras (no caso dessa pesquisa, foram duas) no que concerne ao plano global e à orientação temática das aulas de produção textual, os tipos de discurso, as marcas de pessoa, as vozes, as modalizações e os índices de responsabilização enunciativa, além, é claro, da emergência e emprego de três gestos didáticos (apelo à memória e antecipação didática, formulação de tarefas e emprego de dispositivos didáticos). Tal empreendimento analítico possibilitou que compreendêssemos de modo mais situado como a profissionalidade docente, especificamente ao que diz respeito ao trabalho com produção textual, emerge e se desenvolve durante a realização do estágio supervisionado, momento crucial da formação inicial de professores. Atualmente, no entanto, a crítica que podemos fazer a esse percurso analítico reside na discussão muito superficial que fizemos à época sobre a reconfiguração da noção de gênero que as interações acima transcritas nos permitem vislumbrar (destacadas em negrito) e como isso pode revelar um apropriação bastante frágil dessa noção para o agir docente.

A questão que se coloca não é uma depreciação do trabalho de Liana, à época em formação inicial, como já dissemos. O que a cadeia referencial "um pequeno artiguinho de opinião $\rightarrow$ um artigo de opinião $\rightarrow$ um texto com introdução - argumentos - conclusão" nos possibilita agora tensionar é como, ao longo de sua formação universitária, Liana foi 
experienciando a noção de gênero e a construção de um trabalho de ensino pautado por ela. Se, na introdução do procedimento didático escolhido (sequência didática), a aluna-professora consegue nomear consistentemente o gênero a ser produzido e construir com os alunos uma situação de produção que transforma o gênero em objeto de ensino e de aprendizagem, a sequência da interação nos permite vislumbrar a emergência de práticas sedimentadas no ensino da argumentação, segundo as quais para produzir um texto argumentativo, basta seguir a tríade introdução-desenvolvimento-conclusão. Nesse sentido, coexistem no trabalho real de Liana representações diversas sobre o trabalho com gêneros em sala de aula.

Nosso percurso de pesquisa partiu de uma compreensão de que o trabalho com gêneros potencializa, sim, o desenvolvimento linguístico dos alunos, mas que isso requer, no entanto, um professor mais bem preparado para lidar com os desafios que esse trabalho apresenta. Nosso segundo movimento de pesquisa, ao focalizar a emergência da profissionalidade docente no trabalho com gêneros de texto permitiu concluir que ainda há espaço para seguirmos investindo na construção de novas formas de atuação no trabalho docente. Se a ruptura inicialmente por nós observada dizia respeito à insegurança dos professores já formados em desenvolver uma sequência didática sozinhos, ao observarmos isso no trabalho de alunas-professoras, percebemos que essa questão estava se modificando - ainda que lentamente e com algumas fragilidades. Nesse sentido, a continuidade das pesquisas e ações de formação assentadas na noção de gênero de texto é que permitem que, aos poucos, possamos ir ressignificando as experiências de formação de professores para o trabalho com gêneros na escola.

Uma contribuição que vale ser registrada aqui é que, a partir dos resultados da pesquisa com alunas-professoras, no contexto da universidade que sediou a pesquisa anteriormente relatada, algumas disciplinas do Curso de Letras voltadas à formação de professores foram revisitadas, incorporando algumas das discussões e propostas de trabalho que nosso grupo de pesquisa vem desenvolvendo para solidificar o trabalho com gêneros de texto nas aulas de língua portuguesa. Trata-se, por exemplo, do trabalho com projetos didáticos de gênero - PDG - (GUIMARÃES; KERSCH, 2012; 2014), construção essa que emergiu no contexto de nosso terceiro ângulo de entrada no trabalho com gêneros e que topicalizaremos na próxima seção.

\section{GÊNEROS E DESENVOLVIMENTO PROFISSIONAL DOCENTE}

A articulação entre a noção de gêneros de texto e o desenvolvimento profissional docente passou a ser discutida em nosso grupo a partir de dois projetos de pesquisa que motivaram tanto a continuidade na exploração das possibilidades de didatização de gêneros no ensino de língua portuguesa quanto a mudança de foco analítico: como a formação continuada de professores pode nisso impactar?

O primeiro projeto, intitulado "Por uma formação continuada cooperativa para o desenvolvimento do processo educativo de leitura e produção textual escrita no Ensino Fundamental" (Observatório da Educação/Capes 2011-2014) permitiu nossa aproximação com a rede municipal de ensino que se tornou parceira dos trabalhos que vimos desenvolvendo no que concerne tanto à formação de professores quanto ao desenvolvimento/consolidação de (novas) práticas de ensino de língua portuguesa assentadas no trabalho de didatização de gêneros de texto. Esse projeto foi desenvolvido tendo como alicerce a possibilidade de constituir, de forma cooperativa, em conjunto com professores do Ensino Fundamental, a mudança de paradigmas que ainda perseveram nas salas de aula de língua portuguesa - entre eles, o trabalho com produção textual pouco informado por uma concepção interacionista de linguagem, a inter-relação nem sempre evidente entre os processos de leitura, escrita, análise linguística e produção de texto, além, é claro, da compreensão de que todo trabalho com a língua(gem) em sala de aula deve ser vetor de desenvolvimento de (novos e multi) letramentos. 
Em Carnin e Guimarães $(2015 ; 2016)$ procuramos evidenciar quais princípios nortearam o trabalho de formação continuada de professores de língua portuguesa que desenvolvemos no âmbito desse projeto de pesquisa. Grosso modo, partimos do princípio de que um trabalho cooperativo de formação e pesquisa poderia contribuir para diminuirmos a assimetria entre quem produz o conhecimento científico legitimado institucionalmente (a academia) sobre ensino de língua materna e quem (potencialmente) o mobiliza para seu agir didático (o professor em atuação na Educação Básica). Na esteira desse princípio, procuramos desenvolver, em conjunto com os professores que participaram das formações continuadas que oferecemos entre os anos 2011-2013, outras formas de compreender e significar o trabalho com gêneros em sala de aula - e, neste momento da pesquisa, para além dela. Desse trabalho cooperativo de formação de professores, em que as vozes que se faziam ouvir nos diálogos promovidos não eram apenas aquelas constantemente validadas pela academia (pesquisadores e/ou teorias consagrados...), mas também aquelas advindas da sala de aula, do saber prático, da experiência cotidiana do fazer escolar, emergiu, a partir de uma (co)construção coletiva, a possibilidade de trabalho com gêneros naquilo que passamos a nomear como "projetos didáticos de gênero - PDG" (GUIMARÃES; KERSCH, 2012; 2014). Em linhas gerais, podemos dizer que PDG é uma proposta metodológica de didatização de gêneros que traz como diferencial o fato de ser um projeto de ensino que pode ir além do trabalho com um gênero, que articula tanto a perspectiva de trabalho das sequências didáticas advindas do quadro interacionista sociodiscursivo quanto a perspectiva dos projetos de letramento oriunda dos estudos de letramento. Nesse sentido, um dos diferenciais do PDG é o trabalho com leitura lado a lado com o trabalho de produção textual. Além disso, trata-se de um projeto de ensino que procura articular uma sequência de atividades que, potencialmente, se realizará dentro e fora da escola, de forma a garantir que o(s) gênero(s) tratado(s) esteja(m) realmente ligado(s) a uma prática social, além de desenvolver as capacidades de linguagem dos aprendizes. Na gênese desse conceito está a ambição de poder contribuir para a ampliação da participação social dos estudantes (e professores), de suas formas de ser, estar e agir no mundo de maneira crítica, diversificada, criativa e atuante, auxiliando na (re)construção de sentidos para a prática escolar e para o papel de cada aprendiz/usuário da língua no mundo, considerando, especificamente o contexto sócio-histórico de cada grupo escolar para o qual um PDG pode ser projetado.

Como o percurso de pesquisa que vimos relatando aqui permite observar, nosso ponto de ancoragem para a didatização de gêneros foi, desde o início, o trabalho desenvolvido pela equipe de Didática de Línguas da Universidade de Genebra com sequências didáticas. O caráter sistemático e modular de trabalho com gêneros proposto por esse dispositivo didático segue orientando nosso trabalho de pesquisa e formação. Contudo, a partir desse projeto, passamos a aprofundar nosso diálogo com os estudos de letramento, notadamente para ampliar nossa perspectiva de trabalho com leitura e escrita como práticas sociais que emergem (ou podem emergir) de diversas práticas de (novos e multi) letramentos que os alunos estejam envolvidos (ou possam vir a se envolver).

Conforme já enunciamos em outro momento, e aqui reiteramos, é válido destacar que:

[...] por ser uma proposta de didatização de gêneros realizada no âmbito de uma formação continuada, que levava aos professores conceitos que procuravam desconstruir paradigmas vigentes nas suas salas de aula, a construção conjunta (da noção de PDG) e, mais ainda, a inserção do professor da educação básica (e também de seus alunos) no processo de definição dos gêneros que foram/são objetos de ensinoaprendizagem em sala de aula, o PDG auxiliou no engajamento dos professores e também no desenvolvimento de um sentimento de pertença e valorização do seu(s) saber(es), o que [...] pode ter contribuído para o seu desenvolvimento profissional (CARNIN; GUIMARÃES, 2015, p. 368-269). 
O percurso de formação continuada que desenvolvemos entre 2011-2013, em que muitos professores estiveram conosco ano após ano, permitiu que aguçássemos nosso olhar para a hipótese sugerida por Machado e Lousada (2010): o trabalho com diferentes gêneros, mesmo a apropriação de diferentes gêneros de texto pelo professor, parece influenciar profundamente a construção de conhecimentos e pode impactar no desenvolvimento profissional docente. Em Carnin (2015) exploramos essa hipótese mais a fundo, a partir de um corpus de dados gerados no percurso de formação continuada desenvolvida. A partir da escrita do professor para agir (escrita praxiológica) e da escrita do professor para significar/construir conhecimento (escrita epistêmica), tomando a noção de gênero de texto como eixo articulador da investigação, evidenciamos que a apropriação da noção de gênero e sua verbalização em diferentes produções escritas (um planejamento didático e um artigo acadêmico) nos permite apreender traços de seu desenvolvimento profissional e quais características linguísticodiscursivas, derivadas da identificação e análise da adoção de diferentes tipos de discurso (BRONCKART, 1999), revelam os modos de raciocínio empregados pelos professores quando enunciam seu conhecimento praxiológico e/ou epistêmico sobre gêneros de texto.

O segundo projeto, cujo nome é "Formação continuada e comunidades de desenvolvimento profissional: aproximações teórico-práticas" (CNPq 2016-2020), desafia-nos a avançar em três frentes: (i) a consolidação do trabalho com projetos didáticos de gênero (PDG) como uma opção metodológica para o ensino de língua materna na escola; (ii) o desenvolvimento de um "modelo" de formação continuada de professores de língua portuguesa ancorado na noção de comunidades de desenvolvimento profissional; (iii) o adensamento das reflexões sobre o papel da apropriação de diferentes gêneros de texto (e, principalmente, da noção de gênero de texto) no desenvolvimento profissional docente.

Nossos primeiros resultados de pesquisa, recortando aqui a questão do ensino da escrita, iluminam o que vimos discutindo ao longo deste artigo, permitem-nos sinalizar alguns acertos do percurso que vimos construindo - e também delimitar com mais clareza alguns aspectos que merecem ser mais bem investigados, como discutiremos em nossas considerações finais. Em Guimarães e Carnin (2019), ao refletirmos sobre o modelo de formação continuada que estamos desenvolvendo, enfocamos mais detidamente as representações sobre o ensino da escrita que emergem a partir de uma atividade de intervenção formativa por nós desenvolvida. Essa primeira discussão de dados permitiu que, na análise das verbalizações produzidas pelas professoras em formação, identificássemos quais as concepções de ensino da escrita guiavam as práticas de ensino das professoras (em linhas gerais, identificamos a predominância de uma concepção de ensino da escrita com foco na língua e pouco foco na interação por meio da escrita, por exemplo). Dois textos mais recentes permitem-nos também fazer avançar na compreensão do ensino da escrita a partir do trabalho com gêneros de texto que defendemos e que procuramos desenvolver com os professores em formação continuada. Em Carnin (2020), ao analisarmos sequências interacionais de atividades de formação continuada voltadas ao trabalho com ensino da escrita, observamos que há também, nas verbalizações produzidas por professoras em formação continuada, pistas de desenvolvimento profissional que podem ser apreendidas e classificadas de acordo com o que Mattéï-Mieusset et al. (2019) denominam de fases do desenvolvimento profissional docente. Uma limitação desse estudo, no entanto, diz respeito à não associação dessa análise realizada com, por exemplo, estratégias de formação de formadores para que, atentos a tais pistas, possamos (re)encaminhar ou (res)significar o trabalho de formação em curso. Por fim, a pesquisa de Motta (2020), entre outras coisas, revela um interessante aspecto da aposta que vimos fazendo ao articular as três frentes de trabalho que direcionam nosso mais recente trabalho de pesquisa (acima mencionada): a apropriação de conceitos-chave para o trabalho do docente de língua portuguesa (entre eles do de PDG, mas 
também os de leitura, escrita e, principalmente, gênero de texto como práticas sociais) é um vetor importante de desenvolvimento profissional. Para ilustrar essa perspectiva, vejamos a interação entre Luíza (nome fíctício), coordenadora pedagógica, e Antônio e Júlia (nomes fictícios), dois dos formadores, capturada durante um dos encontros da formação continuada que desenvolvemos em 2018.

Excerto 3 - reflexões sobre mudanças na prática docente

LUÍSA: eu vejo assim, eu não consigo falar muito da prática, "ah, o que mudou na minha prática como professora", > porque eu não tô em sala de aula $<$, mas a $\uparrow$ minha prática como coordenadora $>$ mudou mu:ito durante todo o - (.) né, e eu (.) acho que poder tá conversando com os professores, tá levando - (.) a gente não tem (.) PDG:s acontecendo na escola, né:, tem algumas tentativas, a Ivone (.) seguiu tentando, a Carla também seguiu tenta::ndo, né, mas a gente tá discutindo as práticas assim

$\begin{array}{ll}\text { ANTÔNIO: } & \text { [isso] } \\ \text { LUÍSA: } & \text { que envolvem ((gesticula com as mãos)) } \\ \text { JÚLIA: } & =\text { as concepções, né } \\ \text { LUÍSA: } & {[\mathrm{i}: \text { :sso }]}\end{array}$

Apesar de breve, o excerto acima permite-nos elucidar que o trabalho que vimos desenvolvendo, embasado, como já dissemos, em larga medida no trabalho de didatização de gêneros para o ensino de língua materna, na aposta no trabalho com PDG como uma opção metodológica, sendo esta fortemente assentada no trabalho contínuo de formação de professores em e para seu local de trabalho e no adensamento de nossa compreensão sobre o fenômeno do desenvolvimento profissional docente parece ser um caminho trabalhoso, mas profícuo, de (res)significar o trabalho com gêneros de texto, desde a formação acadêmica (seja ela inicial ou mesmo continuada) até a prática de sala de aula. É no diálogo constante de e com múltiplas vozes e experiências que poderemos (re)pensar linhas de continuidade e de crescimento para o trabalho assentado na noção de gêneros de texto em contextos de ensino de língua portuguesa e de formação de professores. É a partir desse contínuo diálogo, também entre universidade e escola, no qual as vozes de ambas as partes podem ser ouvidas e significadas que poderemos chegar (ou consolidar) a proposição de (novas) formas de atuação pedagógica e também de desenvolvimento profissional docente.

\section{ENCERRANDO A REFLEXÃO, AMPLIANDO AS DISCUSSÕES}

Se, à luz da epígrafe que selecionamos para este texto, podemos compreender que "crescimento é a síntese de mudança e continuidade, e onde não há continuidade não há crescimento", boa parte dos esforços que empreendemos na reflexão aqui apresentada foram produzidos na direção de evidenciar que temos trabalhado, ao longo dos últimos 20 anos, em prol de um crescimento acerca da compreensão, adoção e difusão do trabalho com (a didatização de) gêneros de texto no ensino de língua portuguesa. Entre a mudança que relatamos (de foco analítico e de intervenção) à continuidade no trabalho preocupado com a ressignificação do percurso entre a formação (acadêmica) e a prática (de sala de aula), a síntese que aqui propusemos baseou-se na reflexão crítica sobre nossa experiência de trabalho e de pesquisa a partir da noção de gênero de texto. Para ilustrar esse percurso, optamos pela ênfase nos trabalhos que enfocaram a escrita e seu ensino, embora saibamos (e tenhamos desenvolvido 
também) trabalhos com outras dimensões associadas ao ensino baseado na noção de gêneros de texto (como a leitura, a oralidade e também a análise linguística). No exercício de revisitar a trajetória de pesquisa que vimos construindo, procurando fazer uma (meta)análise de alguns de nossos trabalhos de investigação, identificando os desafios enfrentados, as limitações de nossas pesquisas e também suas potencialidades e perspectivas, queremos encerrar as reflexões que empreendemos neste artigo apresentando alguns desdobramentos, linhas de mudança e/ou de continuidade que a construção deste texto nos permitiram vislumbrar até o momento. São, à guisa de conclusão, inquietações que vamos partilhar, ensejando que o debate aqui iniciado possa ser ampliado e promova novos diálogos sobre o trabalho com gêneros de texto/discurso no ensino de língua materna. Entendemos que ainda são necessárias pesquisas que:

- permitam adensar a compreensão sobre os modos de apropriação da noção de gênero de texto/discurso por professores (em formação inicial ou continuada) e seu impacto no trabalho de ensino;

- possibilitem construir modos de incrementar/diversificar o repertório de gêneros trabalhados pelos professores (e, também, os gêneros de domínio dos próprios professores);

- ressignifiquem o trabalho com gêneros e análise linguística/gramática, especialmente quando se pensa no impacto dessa articulação para a produção de textos em cenário escolar;

- aperfeiçoem e disseminem mais amplamente maneiras de mensurar de modo mais sistemático os impactos do trabalho com gêneros nas aprendizagens discentes;

- promovam/ampliem o(s) diálogo(s) sobre o trabalho com gêneros na escola (mais vozes sendo ouvidas e/ou legitimadas) e construção conjunta de conhecimentos com os professores, considerando também os saberes da prática na construção de objetos de reflexão teórica.

Talvez possamos, à luz desses desdobramentos, daqui a algum tempo, promover novas sínteses no contexto do trabalho com gêneros de texto/discurso no ensino de língua materna.

\section{REFERÊNCIAS}

AEBY DAGHÉ, S.; DOLZ, J. Des gestes didactiques fondateurs aux gestes spécifiques à l'enseignement/apprentissage du texte d'opinion. In: BUCHETON, D.; DEZUTTER, O. (Orgs.). Le développement des gestes professionnels dans l'enseignement du français: un défi pour la recherche et la formation. Bruxelles: De Boeck, 2007. p. 83-105.

BARBOSA, J. P. Notícia. São Paulo: FTD, 2001.

BAWARSHI, A. S.; REIFF, M. J. Gênero: história, teoria, pesquisa, ensino. Tradução Benedito Gomes Bezerra. São Paulo: Parábola, 2013.

BEZERRA, B. G. Gêneros no contexto brasileiro: questões [meta]teóricas e conceituais. São Paulo: Parábola Editorial, 2017.

BRASIL. Parâmetros Curriculares Nacionais: terceiro e quarto ciclos do ensino fundamental: língua portuguesa. Ministério da Educação e Cultura. Secretaria de Educação 
Fundamental. Brasília, DF: MEC/SEF, 1998. Disponível em: http://portal.mec.gov.br/seb/arquivos/pdf/portugues.pdf. Acesso em: 20 mar. 2020.

BRONCKART, J. P. Os gêneros de texto, quadros organizadores da "verdadeira vida" dos signos. In: LOUSADA, E. G.; BUENO, L.; GUIMARÃES, A. M. M. (Orgs.). As unidades semióticas em ação: estudos linguísticos e didáticos na perspectiva do Interacionismo Sociodiscursivo. Campinas: Mercado de Letras, 2017. p. 37-50.

BRONCKART, J. P. Atividade de linguagem, discurso e desenvolvimento humano. Campinas: Mercado de Letras, 2006.

BRONCKART, J. P. Atividade de linguagem, textos e discursos: por um interacionismo sócio-discursivo. São Paulo: EDUC, 1999.

BRONCKART, J. P. O agir nos discursos. Campinas: Mercado de Letras, 2008.

BRONCKART, J. P. Postfácio: ensinar: um "métier” que, enfim, sai da sombra. In: ABREUTARDELLI, L. S.; CRISTOVÃO, V. L. L. (Orgs.). Linguagem e educação: o trabalho do professor em uma nova perspectiva. Campinas: Mercado de Letras, 2009. p. 161-174.

BRONCKART, J. P. Atividade de linguagem em relação à língua - homenagem à Ferdinand de Saussure. In: GUIMARÃES, A. M. M.; MACHADO, A. R.; COUTINHO, A. (Orgs.). O interacionismo sociodiscursivo: questões epistemológicas e metodológicas. Campinas, SP: Mercado de Letras, 2007. p. 19-42.

CARNIN, Anderson. Entre a formação inicial de professores de Língua Portuguesa e o trabalho real: a (co)construção do objeto de ensino produção textual escrita. Dissertação (Mestrado em Linguística Aplicada) - Programa de Pós-Graduação em Linguística Aplicada, Unisinos, São Leopoldo, RS, 2011.

CARNIN, Anderson. Na escrita do professor, um caminho possível para a análise do (seu) desenvolvimento profissional. Tese (Doutorado em Linguística Aplicada) - Programa de Pós-Graduação em Linguística Aplicada, Unisinos, São Leopoldo, RS, 2015.

CARNIN, A. Sobre interação e intervenção formativas em contexto de desenvolvimento profissional docente: reflexões em curso. In: GUIMARÃES, A. M. M.; CARNIN, A.; LOUSADA, E. G. (Org.). O Interacionismo Sociodiscursivo em foco: reflexões sobre uma teoria em contínua construção e uma práxis em movimento. Araraquara: Letraria, 2020. p. 4271. E-book. Disponível em: https://www.letraria.net/o-interacionismo-sociodiscursivo/. Acesso em: 20 mar. 2020.

CARNIN, A.; GUIMARÃES, A. M. M. Formação continuada para professores de Língua Portuguesa: interação na base de uma proposta cooperativa? Scripta (PUCMG), v. 19, p. 241262, 2015. Disponível em: https://doi.org/10.5752/P.2358-3428.2015v19n36p241. Acesso em: 20 mar. 2020.

CARNIN, A.; GUIMARÃES, A M. M. Agir linguageiro, tomada de consciência e desenvolvimento profissional do professor em formação continuada. Revista Brasileira de 
Linguística Aplicada - RBLA, v. 16, p. 365-385, 2016. Disponível em: https://doi.org/10.1590/1984-6398201610276. Acesso em: 20 mar. 2020.

DIONÍSIO, Â. P.; MACHADO, A. R.; BEZERRA, M. A. (Orgs.). Gêneros textuais \& ensino. Rio de Janeiro: Lucerna, 2002.

DOLZ, J. Los cinco grandes retos de la formación del profesorado de lenguas. In: V Simpósio Internacional de Estudos de Gêneros Textuais - SIGET, Caxias do SUL: UCS, 2009.

DOLZ, J.; GAGNON, R.; DECÂNDIO, F. Produção escrita e dificuldades de aprendizagem. Campinas, SP: Mercado de Letras, 2010.

DOLZ, J.; NOVERRAZ, M.; SCHNEUWLY, B. Sequências didáticas para o oral e a escrita: apresentação de um procedimento. In: DOLZ, J.; SCHNEUWLY, B. Gêneros Orais e Escritos na Escola. Tradução e Organização de Roxane Rojo e Glaís Sales Cordeiro. Campinas, SP: Mercado de Letras, 2004. p. 95-128.

DOLZ, J.; SCHNEUWLY, B. Os gêneros escolares - das práticas de linguagem aos objetos de ensino. Revista Brasileira de Educação, ANPED, n. 11, p. 5-16, 1999. Disponível em: http://anped.tempsite.ws/novo_portal/rbe/rbedigital/RBDE11/RBDE11_03_BERNARD_E J OAQUIM.pdf. Acesso em: 20 mar. 2020.

DREY, R. F.; GUIMARÃES, A. M. M. O enfoque da multimodalidade na análise de interações professor-alunos. Letras (UFSM), v. 22, p. 153-176, 2012. Disponível em: https://periodicos.ufsm.br/letras/article/view/12195/7589. Acesso em: 20 mar. 2020.

DREY, R. F.; GUIMARÃES, A. M. M. Reflexões sobre a formação inicial e a constituição da profissionalidade docente. DELTA. Documentação de Estudos em Linguística Teórica e Aplicada (PUCSP), v. 32, p. 23-44, 2016. Disponível em: http://www.scielo.br/pdf/delta/v32n1/0102-4450-delta-32-01-00023.pdf. Acesso em: 20 mar. 2020.

GERALDI, J. W. Concepções de linguagem e ensino de português. In: GERALDI, J. W. (Org.). O texto na sala de aula. Cascavel: Assoeste, 1984, p. 41-49.

GOMES-SANTOS, Sandoval Nonato. A escrita nas formas do trabalho docente. Educ. Pesqui., São Paulo, v. 36, n. 2, p. 445-458, ago. 2010. Disponível em: http://www.scielo.br/scielo.php?script $=$ sci arttext\&pid=S151797022010000200002\&lng=en\&nrm=iso. Acesso em: 20 mar. 2020.

GUIMARÃES, A.M.M.; CORDEIRO, G.S.; AZEVEDO, I.C.M. Realidades sociais diferentes e gêneros textuais: duas experiências no contexto brasileiro. Moara, v. 26, p.53-77, jul. a dez. 2006.

Guimarães, A. M. M. Constituição da Profissionalidade do Professor de Língua Portuguesa: a formação de futuros docentes em foco. Projeto de Pesquisa (mímeo), São Leopoldo, 2009. 
GUIMARÃES, A. M. M. Construindo propostas de didatização de gênero: desafios e possibilidades. Linguagem em (Dis)curso, v. 6, p. 4-12, 2006. Disponível em: http://www.portaldeperiodicos.unisul.br/index.php/Linguagem_Discurso/article/view/341/362 Acesso em: 20 mar. 2020.

GUIMARÃES, A. M. M. Desenvolvimento da narrativa e o processo de construção social da escrita. Projeto de Pesquisa (mímeo), São Leopoldo, 2003.

GUIMARÃES, A. M. M. Desenvolvimento de narrativas e o processo de construção social da escrita. Calidoscópio, São Leopoldo, v. 2 n. 2, p. 67-74, dez. 2004. Disponível em: http://revistas.unisinos.br/index.php/calidoscopio/article/view/6454. Acesso em: 20 mar. 2020.

GUIMARÃES, A. M. M. Gêneros textuais e ensino de língua materna: entre o caminho e a pedra. Revista Brasileira de Linguística Aplicada - RBLA, Belo Horizonte, v. 10, n. 2, p. 421-438, 2010. Disponível em: http://www.scielo.br/scielo.php?script $=$ sci arttext\&pid $=\mathrm{S} 1984-$ 63982010000200008\&lng=en\&nrm=iso. Acesso em: 20 mar. 2020.

GUIMARÃES, A. M. M.; KERSCH, D. F. A caminho da construção de projetos didáticos de gênero. In: GUIMARÃES, A. M. M.; KERSCH, D. F. (Orgs.). Caminhos da construção: projetos didáticos de gêneros na sala de aula de língua portuguesa. Campinas: Mercado de Letras, 2012. p. 21-44.

GUIMARÃES, A. M. M.; KERSCH, D. F. Explorando os projetos didáticos de gênero como um caminho metodológico. In: GUIMARÃES, A. M. M.; KERSCH, D. F (Orgs.). Caminhos da construçãa: projetos didáticos de gênero no domínio do argumentar. Campinas: Mercado de Letras. 2014. p. 17-38.

GUIMARÃES, A. M. M.; CAMPANI-CASTILHOS, D.; DREY, R. F. Gêneros de texto no dia-a-dia do Ensino Fundamental. Campinas: Mercado de Letras, 2008.

GUIMARÃES, A. M. M.; CARNIN, A. Gêneros de texto, escrita e uma proposta de formação continuada para o desenvolvimento profissional docente. In: NASCIMENTO, E. L.; CRISTOVÃO, V. L. L.; LOUSADA, E. G. (Orgs.). Gêneros de texto/discurso: novas práticas e desafios. Campinas: Pontes, 2019. p. 85-112.

GUIMARÃES, A. M. M.; CORDEIRO, G. S.; AZEVEDO, I. C. M. Realidades sociais diferentes e gêneros textuais: duas experiências do contexto escolar brasileiro. MOARA, v. 26, p. 53-77, 2006. Disponível em: https://periodicos.ufpa.br/index.php/moara/article/view/3311. Acesso em: 20 mar. 2020.

GUIMARÃES, A. M. M.; DREY, R. F.; CARNIN, A. Parece difícil e é mesmo: sobre a dificuldade de falar sobre o trabalho docente na sala de aula. In: GUIMARÃES, A. M. M.; CORRÊA, M. C. (Orgs.). Formação continuada de professores de língua portuguesa: desafios e possibilidades. Santa Maria: PPGL Editores, 2012, p. 155-186.

MACHADO, A. R.; BRONCKART, J. P. (Re-)configurações do trabalho do professor construídas nos e pelos textos: a perspectiva metodológica do grupo ALTER-LAEL. In: 
MACHADO, A. R.; CRISTOVÃO, V. L. L.; ABREU-TARDELLI, L. S. (Orgs.). Linguagem e educação: o trabalho do professor em uma nova perspectiva. Campinas: Mercado de Letras, 2009. p. 31-77.

MACHADO, A. R.; LOUSADA, E. G. A apropriação de gêneros textuais pelo professor: em direção ao desenvolvimento pessoal e à evolução do "métier". Linguagem em (Dis)curso, Palhoça, SC, v. 10, n. 3, p. 619-633, set./dez. 2010. Disponível em: http://www.scielo.br/pdf/ld/v10n3/09.pdf. Acesso em: 20 mar. 2020.

MACHADO, A. R. A perspectiva interacionista sociodiscursiva de Bronckart. In: MEURER, J. L.; BONINI, A.; MOTTA-ROTH, D. (Orgs.). Gêneros: teorias, métodos, debates. São Paulo: Parábola Editorial, 2005. p. 237-259.

MACHADO, A. R. Para (re-)pensar o ensino de gêneros. Calidoscópio, São Leopoldo, v. 2, n. 1, p. 17-28, 2004. Disponível em:

http://revistas.unisinos.br/index.php/calidoscopio/article/view/6478. Acesso em: 20 mar. 2020.

MATÊNCIO, M. L. M. Concepções de linguagem e o ensino da língua materna (ou por que a escola faz o que faz?). In: MATÊNCIO, M. L. M. Leitura, produção de textos e a escola: reflexões sobre o processo de letramento. Campinas, SP: Mercado de Letras, 1994. p. 65-78.

MATTÉÏ-MIEUSSET, C. et al. Développement professionnel d'enseignants et verbalisation au sein d'un dispositif d'accompagnement pluriel. Raisons éducatives, Genève, v. 23, no. 1, 2019, p. 71-94. Disponível em: https://www.cairn.info/revue-raisons-educatives-2019-1-page71.htm. Acesso em: 20 mar. 2020.

MOTTA, C. G. A (trans)formação continuada como vetor de e para inovação em contexto(s) de ensino da escrita. Dissertação (Mestrado em Linguística Aplicada) Programa de Pós-Graduação em Linguística Aplicada, Unisinos, São Leopoldo, RS, 2020.

ROJO, R. (Org.). A prática de linguagem em sala de aula: praticando os PCNs. Campinas, SP: Mercado de Letras, 2000.

SCHNACK, C. M.; PISONI, T. D.; OSTERMANN, A. C. Transcrição de fala: do evento real à representação escrita. Entrelinhas, São Leopoldo, v. 2, n. 2, 2005.

SCHNEUWLY, B.; DOLZ, J. Gêneros Orais e Escritos na Escola. Tradução e Organização de Roxane Rojo e Glaís Sales Cordeiro. Campinas, SP: Mercado de Letras, 2004.

VOLOCHINOV, V. La structure de l'enoncé. In: TODOROV, T. (Org.). Mikhail Bakhtine: le príncipe idéologique. Paris: Seuil, 1981 [1930]. p. 287-318.

Recebido em: 20 de março de 2020

Aceito em: 20 de maio de 2020

Publicado em Setembro de 2020 